\title{
Evaluation of efficacy, expulsion and safety of post-placental and intra- cesarean insertion of intrauterine contraceptive devices
}

\author{
Swati Singh $^{1}$, Renu Malik ${ }^{1}$, Ravinder Ahalawat ${ }^{2}$, Bal Krishan Taneja $^{3}$
}

\author{
${ }^{1}$ GH Rohtak, Haryana, India \\ ${ }^{2}$ AIIMS Delhi, India \\ ${ }^{3}$ Gaba Hospital, Yamunanagar, Haryana, India
}

Received: 19 October 2015

Accepted: 23 November 2015

\section{* Correspondence:}

Dr. Swati Singh,

E-mail: swati0011singh@gmail.com

Copyright: (C) the author(s), publisher and licensee Medip Academy. This is an open-access article distributed under the terms of the Creative Commons Attribution Non-Commercial License, which permits unrestricted non-commercial use, distribution, and reproduction in any medium, provided the original work is properly cited.

\section{ABSTRACT}

Background: The objective of the study was to evaluate the safety and efficacy of immediate postpartum intrauterine contraceptive device (PPIUCD) insertion in women delivering vaginally or by cesarean section.

Methods: This prospective study was carried out at General Hospital [Tertiary care] from August 2014 to September 2015. All antenatal patients admitted for delivery to our hospital were counseled for PPIUCD. Also consent was taken from those who opted for PPIUCD insertion.

Results: A total of 2016 women were counseled for PPIUCD adoption. Out of this, 1312 women accepted this method. Total number of deliveries during the study period was 2835 . Total acceptance rate was $46.27 \%$. The expulsion rate was $10.63 \%$ while removal rate was $7.74 \%$. Out of 555 women who came for follow up, 453 women continued PPIUCD. Thus, continuation rate was $81.62 \%$.

Conclusions: PPIUCD is easily accessible, reversible and cost effective contraceptive method for most postpartum women specially lactating women.

Keywords: Intrauterine device, Postpartum contraception, PPIUCD

\section{INTRODUCTION}

India is the second most populated country in the world after China with more than a billion people. India has highest number of maternal death in the world. Maternal mortality rate in India is 16.3 while it is only 0.5 in USA. One of the reasons of increased maternal morbidity and mortality is short interval between births due to limited choice of family planning services, fear about side effects of contraceptive method and lack of information.

In India, current method of family planning is female sterilization (34\%- most common), OCP's (4\%), IUD $(2 \%)$, condoms $(6 \%)$, any traditional method $(1 \%)$ and non-user $(46 \%)$. The modern IUCD is highly effective, safe, long acting, coitus independent, cost effective and rapidly reversible method of contraception with fewer side effects. Many women also find the IUCD to be very convenient because it requires action once it is in place.

Family planning can avert nearly one-third of maternal deaths and $10 \%$ of child mortality when couples space their pregnancies more than two years apart. ${ }^{1}$ Postpartum women need a range of effective contraceptive methods to be able to prevent unplanned pregnancy, within a short interval and at the same time not interfere with lactation.

Moreover, women are more strongly motivated to begin contraception in the postpartum period. This also has the advantage of being convenient for both patients and health care providers. ${ }^{2}$ 
According to WHO Medical Eligibility Criteria, an IUCD can be inserted in the 48 hours postpartum, referred to as Postpartum IUCD (PPIUCD), or after 4 weeks following delivery. ${ }^{3}$ A 2010 Cochrane review concluded that PPIUCD was a safe and effective contraceptive method.

In India, the 2005-06 National Family Health Survey (NFHS) reported that $61 \%$ of births were spaced less than three years. ${ }^{4}$ IUCDs are used by only $2 \%$ of current users of contraception in India. ${ }^{4}$ About $65 \%$ of women in the first year of postpartum had an unmet need for family planning. This approach of immediate postpartum IUCD insertion is more applicable to our country where delivery may be the only time when a healthy woman comes in contact with health care personnel. Other advantages of insertion of an IUCD after deliveries are that the discomfort related to the interval insertion can be avoided and any bleeding from insertion will be disguised by lochia. ${ }^{5}$ Also, postpartum IUCD insertion is not associated with an increased risk of infection, uterine perforation, postpartum bleeding or uterine subinvolution. ${ }^{6}$

This study was conducted to evaluate the safety and efficacy of immediate postpartum intrauterine contraceptive device (PPIUCD) insertion in women delivering vaginally or by cesarean section.

The aim and objectives of the study was to determine percentage of women accepting immediate PPIUCD insertion, to describe the factors associated with acceptability if immediate PPIUCD insertion in women according to their socio-demographic, age parity and future pregnancy desire, to determine the rate of uterine perforation, expulsion, pelvic infection, missing thread and displacement following PPIUCD insertion among acceptors.

\section{METHODS}

This prospective study was undertaken at General Hospital from August 2014 to September 2015. Data was taken from hospital record for the study period. Following criteria was followed:

\section{Inclusion criteria}

All antenatal patients admitted for delivery to our hospital were counselled for PPIUCD. Also consent was taken from those who opted for PPIUCD insertion.

\section{Exclusion criteria}

1. Women who refused for PPIUCD insertion.

2. Women with any obstetric high risk factor like hypertensive disorders of pregnancy, APH or $\mathrm{PPH}$, anemia $(\mathrm{Hb}<8)$.

3. Known uterine anomaly e.g. bicornuate/ septate uterus, uterine fibroid.
4. Ruptured membranes for more than 24 hours prior to delivery.

5. Women with any medical high risk factor like diabetes mellitus, anemia.

6. Active STD/ or lower genital tract infection or high risk for STD.

Data were recorded on a predesigned proforma.

Insertion technique:

1. Post placental insertion

2. Intra- Cesarean insertion

Post placental Insertion: Insertion was performed using Kelly's forceps. The patient was placed in lithotomy position with buttocks at the edge of the table. Aseptic techniques were followed throughout the procedure. The uterus was palpated to evaluate the height of fundus and its tone. It is important to assess the size of uterus to know whether the threads of PPIUCD are likely to protrude through cervix.

After performing all aseptic techniques, a pair of sterile gloves was worn. The perineum was cleaned with povidone iodine. Sim's speculum was inserted into the vagina. The cervix and vaginal walls were cleaned with cotton swabs. The anterior lip of cervix was held by sponge holder. The IUCD was removed from the insertion sleeve and grasped with the Kelly's forceps using no touch technique. Once it is inserted into the lower uterine segment, other hand was moved to abdomen and placed over fundus and uterus was pushed gently upward to reduce the angle and curvature between the uterus and vagina. IUCD with forceps was moved upwards until it can be felt at the fundus. Then the forceps were opened to release the IUCD and swept to sidewall. Uterus was stabilized until forceps removal was complete. The cervical os was gently inspected for the PPIUCD thread. Sim's speculum was removed.

Intra- Cesarean insertion: The IUCD was removed from insertion sleeve and placed on the sterile field. Uterus is stabilized by grasping it at fundus. IUCD is held between middle and index finger. It was inserted into the uterus through uterine insertion and released at fundus of uterus. Hand was removed slowly from the uterus. Care was taken not to dislodge IUCD as hand is removed. IUCD threads were guided towards the lower uterine segment without disturbing IUCD's fundal position. Care was taken not to include IUCD strings during uterine closure.

Later prior to discharge, patient was told when to return for IUCD follow up. She was also informed about IUCD side effects. She was advised to come back anytime if she has:

a. Foul smelling vaginal discharge different from the usual lochia. 
b. Lower abdominal pain, especially if accompanied by fever, chills.

c. Suspicion that IUCD has fallen out.

\section{RESULTS}

Table 1: Distribution according to age.

\begin{tabular}{|lll|}
\hline Age & $\begin{array}{l}\text { Total No. of women } \\
\text { accepted PPIUCD } \\
(\mathbf{n = 1 3 1 2})\end{array}$ & $\%$ \\
\hline $\begin{array}{l}\text { Less than } 20 \\
\text { years }\end{array}$ & 76 & $5.79 \%$ \\
\hline $20-24$ & 772 & $58.84 \%$ \\
\hline $25-29$ & 350 & $26.67 \%$ \\
\hline $30-34$ & 105 & $8 \%$ \\
\hline 35 or above & 9 & $0.6 \%$ \\
\hline
\end{tabular}

A total of 2016 women were counseled for PPIUCD adoption. Out of this, 1312 women accepted this method. Total number of deliveries during the study period was 2835. Total acceptance rate was $46.27 \%$.

Table 2: Distribution according to parity.

\begin{tabular}{|lll|}
\hline Parity & $\begin{array}{l}\text { Total women accepted } \\
\text { PPIUCD }(n=1312)\end{array}$ & $\%$ \\
\hline P1 & 555 & $42.30 \%$ \\
\hline P2 & 403 & $30.71 \%$ \\
\hline P3 or above & 354 & $26.98 \%$ \\
\hline
\end{tabular}

Table 1 shows age distribution of 1312 women who accepted PPIUCD insertion. Majority of the cases were between the age group of 20-24 years (58.84\%).

Table 3: Educational status.

\begin{tabular}{|c|c|c|}
\hline Education & $\begin{array}{l}\text { Total women } \\
\text { accepted } \\
\text { PPIUCD } \\
(\mathrm{n}=1312)\end{array}$ & $\%$ \\
\hline Illiterate & 241 & $18.36 \%$ \\
\hline Primary/Secondary & 855 & $65.16 \%$ \\
\hline Graduation/Postgraduate & 216 & $16.46 \%$ \\
\hline
\end{tabular}

Table 2 shows distribution of women according to their parity. PPIUC acceptance is more in primigravida women $(42.30 \%)$.

\section{Table 4: Post placental and postpartum (within 48} hours) IUCD insertion.

\begin{tabular}{|ll|}
\hline Postplacental & $701(53.4 \%)$ \\
\hline Postpartum & $611(46.57 \%)$ \\
\hline Total & 1312 \\
\hline
\end{tabular}

Table 5: Awareness about PPIUCD.

\begin{tabular}{|ll|l|}
\hline & Total No. $(n=1312)$ & $\%$ \\
\hline Yes & 912 & $69.5 \%$ \\
\hline No & 400 & $30.48 \%$ \\
\hline
\end{tabular}

\begin{tabular}{|ll|l|}
\hline & Total No. $(\mathbf{n}=1312)$ & $\%$ \\
\hline Yes & 323 & $24.61 \%$ \\
\hline No & 989 & $75.38 \%$ \\
\hline
\end{tabular}

Table 6: Follow up details of PPIUCD acceptors.

\begin{tabular}{|ll|}
\hline Follow up & Number of women $(n=1312)$ \\
\hline Return for follow up & $555(42.30 \%)$ \\
\hline Did not return & $757(57.69 \%)$ \\
\hline
\end{tabular}

Table 3 shows educational profile of women who accepted PPIUCD. Acceptance of PPIUCD was higher among women with primary and/ or secondary education $(65.16 \%)$ than those with no formal education $(18.36 \%$ and $16.46 \%)$.

Table 7: Complications among PPIUCD acceptors in the study.

\begin{tabular}{|lll|}
\hline Complications & No. of women & $\%$ \\
\hline Bleeding & 206 & $15.70 \%$ \\
\hline Expulsion & 59 & $4.49 \%$ \\
\hline Missing thread & 46 & $3.50 \%$ \\
\hline Pelvic infection & 0 & 0 \\
\hline $\begin{array}{l}\text { Pregnancy with IUCD in } \\
\text { situ }\end{array}$ & 0 & 0 \\
\hline
\end{tabular}

Table 4 shows post placental and post-partum PPIUCD insertion among PPIUCD acceptors. Post placental insertion was $53.4 \%$ while postpartum (within 48 hours) was $46.57 \%$.

Table 8: Timing and rate of expulsion in the study.

\begin{tabular}{|ll|}
\hline Time & No. of women $(n=59)$ \\
\hline Within 7 days & 8 \\
\hline Between 7 to 4 weeks & 46 \\
\hline After 4 weeks & 5 \\
\hline
\end{tabular}

The awareness of women about PPIUCD is shown in Table 5. Though the majority of women were aware of $\mathrm{CuT}$ (interval IUCD) but fewer women have heard of insertion in postpartum period $(69.5 \%$ vs $24.61 \%)$.

Table 6 shows follow up details of PPIUCD acceptors. Out of 1312 women, 555 PPIUCD acceptors returned for follow up. 757 women did not return for follow up.

The complications among PPIUCD acceptors are shown in Table 7. Bleeding was the most common complaint 
(15.70\%), followed by expulsion (4.49\%) and missing PPIUCD thread $(3.50 \%)$. No case of perforation or other major complication was found.

Table 9: Reasons of removal of IUCD in the study.

\begin{tabular}{|lll|}
\hline Reasons of removal & No. of women $(\mathrm{n}=\mathbf{4 3})$ & $\%$ \\
\hline Bleeding & 14 & $32.56 \%$ \\
\hline $\begin{array}{l}\text { Changes in } \\
\text { menstrual cycle }\end{array}$ & 3 & $6.98 \%$ \\
\hline $\begin{array}{l}\text { Pressure from } \\
\text { family }\end{array}$ & 11 & $25.58 \%$ \\
\hline Pain abdomen & 7 & $16.28 \%$ \\
\hline $\begin{array}{l}\text { Don't want to } \\
\text { continue }\end{array}$ & 3 & $6.98 \%$ \\
\hline Others & 5 & $11.63 \%$ \\
\hline
\end{tabular}

The timing and rate of expulsion are shown in Table 8 .

Table 9 shows reason of removal of IUCD in the study. Most common reason of removal of PPIUCD in our study was bleeding $(32.56 \%)$. The other reasons of removal of PPIUCD were changes in menstrual cycle $(6.98 \%)$, pressure from family $(25.58 \%)$, pain in abdomen $(16.28 \%)$, do not want to continue $(6.98 \%)$ and others (11.63\&).

Table 10: Continuation rate in the study.

\begin{tabular}{|ll|}
\hline Total insertion of PPIUCD & 1312 \\
\hline Total follow up & 555 \\
\hline Expulsion & $59(10.63 \%)$ \\
\hline Removal & $43(7.74 \%)$ \\
\hline Continuation & $453(81.62 \%)$ \\
\hline
\end{tabular}

The continuation rate of PPIUCD in this study is shown in Table 10. The expulsion rate was $10.63 \%$ while removal rate was $7.74 \%$. Out of 555 women who came for follow up, 453 women continued PPIUCD. Thus, continuation rate was $81.62 \%$.

\section{DISCUSSION}

In our study, total acceptance rate was $46.27 \%$. Majority belonged to age group of $20-24$ years $(58.84 \%)$. This was because they consider PPIUCD as an effective spacing method with no effect on lactation. Alvarez Peyalo et al also found average age of PPIUCD acceptance was $20.6 \%{ }^{7}$

In this study, majority of the women in study population had at least primary level of education. Acceptance of PPIUCD was higher among women with primary and/or secondary education $(65.16 \%)$ than those with formal or higher education $(18.36 \%$ and $16.46 \%)$. This finding confirms importance of education in deciding future pregnancy. This was similar to a study done in Egypt by Safwat A et al. ${ }^{8}$ It shows that education is also a major factor in awareness and acceptance of PPIUCD. The acceptance of PPIUCD was most common among primigravida women $(42.30 \%)$. In case of multiparous women, it was $30.71 \%$. Thus, this finding is similar to Safwat A et al but contrary to that of study by Grimes D et $\mathrm{al}^{9}$ where they found higher acceptance in multiparous clients $(65.1 \%){ }^{8}$

The duration since last child birth was significantly associated with acceptance of PPIUCD. About $72 \%$ of PPIUCD acceptors had their last child birth less than 2 years. Women on first delivery and with short pregnancy interval felt the necessity of a long acting and reliable method of contraception. In a report by WHO in 2006, better family planning and birth spacing services resulted in better maternal and neonatal outcome. The findings in the study indicate towards positive maternal health in future.

During the study, it was found that $24.61 \%$ of women were familiar with PPIUCD, while $75.38 \%$ women have not even heard of PPIUCD. Also, women who knew about PPIUCD's had many misconception and myths about it, like it affects lactation, non reversible method, cause pain, heavy bleeding, hinders coitus etc. These misconceptions during the study were cleared up and women were educated, counseled and motivated about PPIUCD insertion.

In the present study, only $42.30 \%$ returned for follow up while $57.69 \%$ of cases did not return for follow up. 43 cases wanted removal in follow up period due to many reasons. Out of these 43, only 2 cases wanted removal of PPIUCD as they were motivated for permanent sterilization by ASHA worker due to family planning program running in the state. This shows that these ground level workers play an important role in motivating people for this method. XuJx et al found that the follow up rate in their study was $95.5 \% .^{10}$ The importance of follow up visit after PPIUCD insertions is that the women as well as health care providers can be reassured of IUCD placements. In case of expulsion, reinsertion/ other contraceptive method can be provided.

Like other studies bleeding $(15.70 \%)$ out numbers other complication. ${ }^{11}$ But 14 out of 206 insisted on removal, rest retained PPIUCD with reassurance only which speaks of the importance of counseling.

46 women among those inserted with PPIUCD have missing threads during first follow up at 4-6 weeks. In 40 cases, threads were found in cervical canal. Rest 6 cases needed ultrasound and confirmed that the IUCD were in situ. 2 of them insisted on removal. On removal, curling and retraction of thread into uterine cavity were confirmed. No cases of uterine perforation or pregnancy with IUCD in situ were reported during the study. This is in accordance with the study of Shafer MM et al and Ricalde et al where no perforation were observed in PPIUCD. ${ }^{12,13}$ 
No case reported interference of PPIUCD with lactation as also found by Dias S et al. ${ }^{14}$

Tatum HJ et al found that the gross cumulative expulsion rate in their study was $16.2 \%$. In the present study, expulsion rate was $10.63 \% .^{15}$

Chi IC et al found that there is a lower expulsion rate with immediate post-placental insertion than with immediate postpartum insertion. ${ }^{16}$ As well, insertion during cesarean section has a lower expulsion rate than insertion during postpartum (within 48 hours) period. This is likely due to the fact that it is easier to reliably reach the uterine fundus during post placental or cesarean section.

Out of 555 women, who returned for follow up, 453 women continued PPIUCD. Thus, the continuation rate of PPIUCD in this study was $81.62 \%$.

\section{CONCLUSION}

The acceptance of PPIUCD was higher in the present study and it is comparable to other studies done globally. Awareness of the PPIUCD among these women was very poor despite high acceptance. Primigravida had greater acceptance of PPIUCD. Acceptance was high among women who had primary and/or secondary education.

Therefore, PPIUCD was demonstrably safe, having no reported incidence of perforation with low rate of expulsion, pelvic infection and missing threads.

The Government of India is now recommending post placental/ postpartum IUCd insertion because PPIUCD were a safe and effective contraceptive method with no effect on lactation. The Government of India is also providing this service free of cost to the patients. Thus, we can conclude that PPIUCD is easily accessible, reversible and cost effective contraceptive method for most postpartum women specially lactating women.

\section{Funding: No funding sources}

Conflict of interest: None declared

Ethical approval: The study was approved by the Institutional Ethics Committee

\section{REFERENCES}

1. Cleland J, Bernstein S, Ezeh A, Faundes A, Glasier A, InnisJ. Family planning: the unfinished agenda. Lancet. 2006;368:1810-827.

2. $\mathrm{Xu}$ JX, Reusche $\mathrm{C}$, Burdan A. Immediate postplacental insertion of intrauterine device: A review of Chinese and world experiences. Adv Contracept. 1994;10:71-82.

3. World Health Organization: Medical Eligibility Criteria for Contraceptive Use. $4^{\text {th }}$ ed. Geneva: World Health Organization. 2010:3-4.
4. International Institute for Population Sciences (IIPS) and Macro International, 2007. National Family Health Survey (NFHS-3). 2005-06;15-9.

5. Shukla M, Qureshi S, Chandrawati. Post placental intrauterine device insertion- A five yearexperienceat a tertiary care centre in north India. Indian $\mathbf{J}$ Med Res. 2012;136:432-5.

6. ChI-C, Farr G. Postpartum IUD contraception- a review of an international experience. Adv Contracept. 1989;5:127.

7. Alvarez pelayo J, B orbolla Sala ME. IUD Insertion during caesarean section and its most frequent complication. Ginecol Obstet Mex. 1994;62:330-5.

8. Safwat A, Mohamed Momen A, Kamel Omar M. Acceptability for the use of postpartum intrauterine contraceptive devices: assiut experience. Med Princ Pract. 2003;12:170-5.

9. Grimes D, Schulz K, van Vliet H, et al. Immediate post-partum insertion of intrauterine devices: a cochrane review. Hum Reprod. 2002;17(3):549-54

10. Xu JX, rivera R, Dunson Tr, Zhuang LQ, Yang XL, Ma GT, Chi IC. Shanghai municipal family planning commission, People's Republic of china. A comparative study of two techniques used in immediate postplacental insertion of copper T-380 A IUD in shanghai, people's republic of china. Contraception. 1996;54(1):33-8.

11. Celen S, Moroy P, Sucak A. Clinical outcomes of early post placental insertion of intrauterine contraceptive devices. Contraception. 2004;69:27982.

12. El-shafei MM, Mashali A, Hassan EO, El Boghdadi L, El Lakkany N. Post partum and post abortion intra uterine device insertion unmet needs of safe reproductive health: 3 years' experience of a Mansoura university hospital. Egypt Soc Obstet Gynaecol. 2000;26:253-62.

13. Lara RR, Tobias GM, Parez CR, Ramirez NV. Estudiocomparativo al azar entre los dispositivos intrauterinos Multiload Cu375 y $\mathrm{TCu} 380 \mathrm{~A}$ colocados durante ei postparto. Ginecol Obstet Mex. 2006;74:306-11.

14. Diaz S, Zepeda A, Maturana X, Reyes MV, Miranda $P$, Casado ME. Fertility regulation in nursing women. IX. Contraceptive performance, duration of lactation, infant growth, and bleeding patterns during use of progesterone vaginal rings, progestin-only pills, Norplant implants, and Copper T 380-A intrauterine devices. Contraception. 1997;56:223-32.

15. Tatum HJ, Beltran RS, Ramos R, Van Kets H, Sivin I, Schmidt FH. Immediate postplacental insertion of GYNE-T380 and GYNE-T380 postpartum intrauterine contraceptive device. Am J Obstet Gynecol. 1996;175(5):1231-5.

16. Chi IC, Wilkens L, Roger S. Expulsions in immediate postpartum insertion of Lippes Loop D and Copper T IUD's and their counterpart Delta devices-an epidemiological analysis. Contraception. 1985;32:119-34.

Cite this article as: Singh S, Malik R, Ahalawat R, Taneja BK. Evaluation of efficacy, expulsion and safety of post-placental and intra-cesarean insertion of intrauterine contraceptive devices. Int J Reprod Contracept Obstet Gynecol 2015;4:2005-9. 